\title{
"Maybe You Have to be Friends to be Nakama": School Friends and Cultural Logics in the United States and Japan
}

\author{
Amy Damrow \\ Kent State University at Stark \\ Ohio, USA
}

\begin{abstract}
I examine the concept of school friends by drawing on the ideas and experiences of one Japanese boy as he lived and attended school in both the United States and Japan. This ethnographic case study facilitates a comparative analysis of peer relations in schools through centering an 11-year-old's perspective as he participated in and navigated ecological systems in both countries. Data include formal interviews with the youth, his parents, and his teachers, observations in schools in the United States and Japan, eco-maps, community maps, and sociometric questioning over a fifteen-month period. The study identified the strategies used to navigate social spaces, the different logics of school friends in the sociocultural spaces examined, and the subtle ways that particular types of communities are built in classrooms. Implications for teachers, teacher educators, administrators and others interested in building social and cognitive skills and a healthy school climate are discussed.
\end{abstract}

A positive school environment is associated with social, emotional, and physical safety, healthy relationships among students and teachers, and engaged learning and teaching (Brown, Corrigan, \& Higgins-D'Alessandro, 2012; Centers for Disease Control and Prevention, 2009; Furrer, Skinner, \& Pitzer, 2014; Thapa, Cohen, Guffey, \& D’Alessandro, 2013). Although accountability for academic achievement as measured through standardized testing is likely to 
continue to play a prominent role in the United States, there is also renewed interest in harnessing social and emotional learning (SEL) to improve academic development (Melnick, Cook-Harvey, \& Darling-Hammond, 2017; Zins, Bloodworth, Weissberg, \& Walberg, 2007) and to address contemporary problems such as delinquency and bullying (see e.g., Smith \& Low, 2013). According to the Collaborative for Academic, Social, and Emotional Learning (CASEL), SEL is defined as "the process through which children and adults acquire and effectively apply the knowledge, attitudes, and skills necessary to understand and manage emotions, set and achieve positive goals, feel and show empathy for others, establish and maintain positive relationships, and make responsible decisions." In this paper, I build upon the rich literature on the ways that Japanese preschool and elementary education builds whole-class peer groups that facilitate collaboration in learning and enable all students to feel like they belong to a community (Cave, 2007; Hoffman, 2009; Lewis, 1995; Peak, 1991; Sato, 2004; Tsuneyoshi, 2001).

My primary interest is in interpersonal relationships among children in classrooms and the ways in which teachers encourage peer relationships. This "ethnography of the particular" (Abu-Lughod, 1991) draws from a comparative study of schooling in the United States and Japan over a 15-month period from the perspective of Seiji ${ }^{1}$, an 11-year old Japanese boy who successfully participated in both (Damrow, 2014). During our early interviews, Seiji regularly talked about friendship. Consequently, it became a focus of the research. This paper addresses these questions: How did a bilingual and bicultural Japanese boy define and experience friendship in the United States and Japan? How did his ideas about friendship interact with dominant ideas regarding social relations in the classrooms he was a member of and the schools he attended?

\section{Background and Theoretical Framework}

Different disciplines recognize the importance of friendship in children's lives. This study works at the nexus of developmental psychology, sociology, anthropology, comparative research, and teacher education. This mélange reflects my own experiences, scholarly training and interests, and current professional responsibilities. My first professional position after college was as an English teacher in Japan. After returning to the United States, I studied child development within a College of Human Ecology. Over the years, I maintained relationships and conversations with returnee students and their families about the challenges and opportunities cross-cultural living and schooling offered. In addition to working with Japanese children in Japan, my thinking about peer relationships in classrooms informs and has been informed by my work with pre-service teachers both at a large university and at a regional commuter campus in the Midwestern United States. SEL and school climate are a small part of the explicit curriculum in the required introductory courses I teach. However, building a classroom community and facilitating relationship building among my students is "an underground river" in my curriculum (J. Saphier, personal communication, June 12, 2017), because I want these future teachers to experience the powerful learning that is possible when relationships are built and collaboration is facilitated and expected.

Through his ecological theory, Bronfenbrenner (1979) sought to facilitate "the scientific study of the progressive mutual accommodation between an active, growing human being and the changing properties of the immediate settings in which the developing person lives, as this process is affected by relations between these settings, and by the larger contexts in which the 
settings are embedded" (p. 21). I use the model to identify important sites of interaction (primarily classrooms, schools, families, and neighborhoods), analyze interactions between those systems, and locate all settings within a larger system. Hedegaard's (2009) cultural historical activity theory (CHAT) extends Bronfenbrenner's model and emphasizes "the societal institutions and the activity of the person" (p. 65). This lens helped me analyze societal norms and values, institutional perspectives and practices, and the role of children's own views in their development. I was primarily interested in Seiji's words and actions as situated practices, anchored in the settings of his everyday life and activities and the meaning he made of his experiences (Hedegaard \& Fleer, 2008; Hedegaard, Aronsson, Højholt, \& Ulvik, 2012). Bronfenbrenner and Hedegaard were both trained as developmental psychologists, although they also integrate, or their theories are at least compatible with, ideas from the sociological and anthropological literatures on friendship. For example, sociologists push the definition of friendship away from simply dyads and consider children's definitions of their friendships (Corsaro \& Eder, 1990). Anthropologists view children as active agents, emphasize cultural practices, and refrain from seeking universal definitions of concepts (Bell and Coleman, 1999; James, 2013).

International comparative educational research (Alexander, 2000; Bronfenbrenner, 1972; Tobin, Wu, \& Davidson, 1989) and case studies of young immigrants and migrants (Kanno, 2003; Kirova, 2007; Ma, 2010) inform my thinking about the experiences of young bordercrossers as they transition between diverse settings and seek to develop linguistic, social, and academic competencies. This study adds to what we know about students who navigate multiple worlds and adjust to varying expectations. I also hope to amplify the ideas of a boy who was a "first-level consumer of educational services" (Erickson \& Shultz, 1991, p. 481) in both Japan and the United States. Seiji provides a child's sensibilities to our understanding of social interactions in elementary schools and classrooms and can help educators reconsider the idea of school friendships as voluntary relationships.

\section{Situating the Research}

Rather than providing a broad review of research on friendships (see Bagwell \& Schmidt, 2013; Schneider, 2016), I emphasize the literature on children's interactions with peers at school in the United States and Japan and teacher expectations in regard to those interactions. Since most pre-service teachers in the United States encounter the topic of social relationships in schools from required educational psychology courses, I emphasize that research. I use the National School Climate Center's (NSCC) definition of social support among students to frame how a Japanese logic of school friends might play out in an American context. The NSCC defines this dimension of school climate as a "pattern of supportive peer relationships for students, including: friendships for socializing, for problems, for academic help, and for new students." Explicitly linking peer relationships in schools to broad-based friendship is uncommon in the United States, but it is not unprecedented.

\section{Cultural Logics: Friendship in the Elementary Classroom}

While Japanese and American teachers generally both strive for positive school environments that foster learning and classroom community, there is a subtle distinction in the cultural logics that guide those efforts. While individual teachers set the tone in their classroom microsystems, broad cultural ideas in the macrosystem influence where Japanese and American 
elementary educators locate children's friendships, the value they place on those relationships within the schooling endeavor, and the responsibility they accept for facilitating feelings of friendship among all students. In essence, while American students may feel like they are part of the crowd (Blatchford, Bassett, \& Brown, 2005; Jackson, 1968/1990), Japanese children are encouraged to feel like they are part of the team (Lewis, 1995).

Japanese cultural logic: Mina tomodachi (Everyone is a friend). Although Seiji came to the United States as a four-year-old, he was born in Japan and had "learned to go to school" (Peak, 1991) at a Japanese preschool. Preschool in Japan is an important transitional experience where children learn the rules and expectations of shudan seikatsu, or group life (Hendry, 1986; Lewis, 1995; Tobin, Wu, \& Davidson, 1989). Tobin, Hsueh, and Karasawa (2009) note that preschools across Japan seem to follow a "deep cultural logic" that allows children to develop traditional values such as "omoiyari (empathy), kejime (the ability to change one's behavior according to the context), and shudan shugi (social-mindedness)" (p. 240). Japanese elementary schools also intentionally develop these habits of the heart.

Although both American and Japanese preschool and early elementary teachers use the word "friends" or "tomodachi" to refer to all class members and not specifically personal friends, in Japan this strategy is an integral part of the socialization curriculum, extending beyond the early years, and does not reflect individual teacher approach or preference. The central argument in Lewis' (1995) book Educating Hearts and Minds is that "Japanese education succeeds because, early on, it meets children's needs for friendship, for belonging, for opportunities to shape school life" (p. 1, emphasis in original). Japanese elementary school teachers consistently and purposefully use tomodachi to refer to all class members because acquiring relational basics is itself a learning goal, and it facilitates teaching and learning academic content (Lewis, 1995; Sato, 2004).

One strategy for building community is the use of han, or small fixed groups. Throughout the elementary years, Japanese teachers use han to achieve goals of individual expression and reflection and to allow children to engage with the ideas of others around academic, practical, and social tasks (Cave, 2007; Damrow, 2014; Green, 2014). Therefore, most Japanese children become proficient in working as groups by sixth grade. Japanese teachers use the word tomodachi when addressing or referring to their class in part because they are striving to create nakama. Cave (2007) delineates, "Being nakama is a relationship that demands that you give special help and support to one another, regardless of personal likes and dislikes. Calling the class group a nakama is thus to state that its members belong together in a special way-not out of personal volition but simply by virtue of having been placed in the same class - and that they have a special responsibility to one another" (p. 62, emphasis added). Nakama is not something Japanese children choose or choose not to be a part of; it is a concept that is rehearsed through verbal discourse and embodied over time. Of course, groups may also serve an oppressive role. In Japan, whole class bullying is a common form of ijime (Morita, Soeda, Soeda, \& Taki, 1999), although a small group of close friends is also a frequent location for bullying (Morita et al., 1999; Yoneyama \& Naito, 2003). Thus, even though in Japan individual investment in group life tends to be high, belonging to the group has risks. Effective teacher leadership and modeling are needed to set the tone and influence social relationships in individual classrooms.

American cultural logic: Choosing friends. In her 1993 book You Can't Say You Can't Play, Vivian Paley, a kindergarten teacher, chronicled her experience introducing the new rule 
(same as the title of the book) in order to curb the excluding tendencies of some of her students. She writes, "By kindergarten, a structure begins to be revealed.... Certain children will have the right to limit the social experiences of their classmates. Henceforth a ruling class will notify others of their acceptability, and the outsiders learn to anticipate the sting of rejection" (p. 3). Essentially, the phrase, "you can't play" is a "habit of rejection" (Paley, 1993). The danger of habits is that they are often invisible and therefore seen as inevitable and normal.

In the United States, research and practitioner-oriented writing on peer relationships, children's friendships, and children's social development often focuses on children's choices (who is chosen as a friend and who is not) and the child's responsibility to develop his or her own social skills - especially if they are judged as inadequate (see, e.g., Gifford-Smith \& Brownell, 2003; Grusec \& Hastings, 2007; Kostelnik, Stein, Whiren, \& Soderman, 1998; Rubin, Bukowski, \& Laursen, 2009; Blatchford, Pellegrini \& Baines, 2015). In the 2009 Handbook of Peer Interactions, Relationships, and Groups, researchers frequently refer to "rejected children," "non-friends," "low-status children," "isolates," and "popular and unpopular children." Peer groups make decisions on the likability of particular children and pairs of children enter into friend relations by choice (Gifford-Smith \& Brownell, 2003, p. 248). Children develop social and emotional skills as individuals rather than as members of classroom communities. Consider, for example, the opening statement in the final chapter of the above-mentioned handbook:

Based on empirical demonstrations that children who are unable to function adequately with peers are at risk for several forms of concurrent and subsequent maladjustment, clinically oriented peer researchers have recognized the need for the development of intervention strategies. Beginning in the late 1970s, social skill training programs, originally intended to remediate the deficits of clinic populations, were adapted to improve the social behaviors of children who were unaccepted by their peers. (Bierman \& Powers, 2009, p. 603, emphasis added)

Although stated in the negative ("children who are unable to"), capability is key. However, the final part of the second sentence is written in passive tense ("children who were unaccepted by their peers") rather than active tense ("peers rejected [certain] children"). In these sentences, emphasis is placed on the responsibility of individuals to achieve good social relations for themselves. The responsibility of children as members of a group, however, to act, talk and interact in ways that facilitate good social relations with unchosen group members is not addressed. Blaming "unpopular" and "rejected" children, especially young children, for their lack of social skills is unlikely to help them become more socially adept.

Of course, most American teachers do try to foster a sense of community in their classrooms and civility among students. The literature on caring, empathy and perspective-taking suggests that these skills are highly valued (Kostelnik et al., 1998; Noddings, 1992). In addition, cooperative learning, a well-known instructional strategy, emphasizes social interaction and the co-construction of knowledge (Slavin, 1995). However, learning to work as a group is different from merely working in a group (Alexander, 2000; Lewis, 1995). Putting students into groups is not the same as facilitating effective group work that fosters deep learning. 


\section{Design of the Study}

\section{Methods and Methodology}

Bronfenbrenner's (1979) ecological systems theory frames this ethnographic case study. Ecological models place individuals within sites of interaction such as home, school, and neighborhood and then within the increasingly broader systems that influence interactions and meaning making within those sites. In this paper, the school setting was the major site; however, home, neighborhood, and the interactions between and among these settings contributed to my understanding of Seiji's ideas about friendship. The research was conducted in three phases. In phase one, Seiji's family was preparing to return to Japan after living in Michigan for five and a half years. The intentional timing of the return allowed Seiji to begin the school year in Japan in early April with his classmates. The second phase marked a period of adjustment and settling-in soon after the family's return to Japan. The final phase included completion of a year of school in Japan and Seiji's graduation from elementary school. Cultural historical activity theory (Hedegaard, 2009) guided methodological choices and analysis. In each phase, I used the same basic process: interviews with Seiji, his mother, and his teachers; classroom observations; and analysis of documents. In phase two, I also interviewed Seiji's father. Data generation in early phases informed subsequent data generation.

Participants My criteria for selecting participants were both practical and strategic. I describe the parameters and my rationale in more detail elsewhere (Damrow, 2014), but I sought a child in upper elementary school who had lived in the United States for three to five years, who attended a Japanese Saturday supplementary school, whose parent was employed by a Japanese company and who would be returning to Japan in March of the year I began the study. I first met Seiji's family electronically when Aya, Seiji's mother, responded to my recruitment posting on an online Japanese information bulletin board. Once Seiji and Aya agreed to join the study, all settings and secondary participants - Seiji's teachers and his classmates and friends-were implicated rather than chosen. Seiji, his little sister, and his parents came to Michigan in 2003 when Seiji's father accepted an offer to work at a Michigan-based office of his multinational company. As a transnational family, Seiji lived in a comfortable home in a safe neighborhood in both the United States and Japan; he also attended schools with good reputations and experienced teachers. Both of his parents were university graduates.

Ethical Considerations and Researcher Positionality Feminist principles influenced my approach to all aspects of the research as well as my commitments as a researcher. Some of these principles include acknowledging positionality, engaging in research for positive change, discerning ambiguity, validating women's experiences in everyday life, recognizing the importance of context, and explicitly noting that every account of lived experience is partial (Harding, 1987; Kirsch, 1999; Kondo, 1990; Usher, 2000; Wolf, 1992). I see these principles as congruent with an ethical approach to research with children.

My goal for the study as a whole was to contribute to a "growing mosaic of understanding” (Graue \& Walsh, 1998, p. 14) of children's experiences. Seiji's experiences with and views of friendship ultimately helped him successfully navigate within and between multiple worlds, but initially I became interested in friendship because my interviews and conversations with Seiji were saturated with references to friends. Although Seiji was academically successful and enjoyed learning, he reported that the opportunity to interact with other children was the best part of school. Thus, Seiji himself was the stimulus for exploring and analyzing broad cultural ideas about social relationships in classrooms. Emond (2005) warns, "[Ethnography, w]ith 
specific regard to children, requires us to suspend our sense of 'superior' knowledge and to learn the practices and perspectives of those under study" (pp. 136-137). I viewed Seiji as both a collaborative data generator and as a tour guide in the various settings of his day-to-day experiences. And perhaps, in part because he was a Japanese boy, I did not presume to know how he was experiencing any aspect of his life. Rather, my own puzzlement in various settings led me to further inquiry and ultimately to a richer and more nuanced interpretation of Seiji's words, actions, and interactions. The research also honors ethical principles because it is in children's interest to have their social needs met in classrooms, and the findings stand to have a positive impact on their schooling experiences as a whole (Alderson, 1995).

My positionality shifted as I travelled to different contexts. This had implications for what was visible/audible, less visible/audible, and invisible/inaudible to me. My first teaching experience was in Japan, and I had formally studied Japanese for several years, but my cultural and linguistic skills were unexceptional. Although I was a guest in all three schools, the American school was more familiar to me and the Japanese schools were less so. Aya had invited me to stay with her family when I came to Japan. I enthusiastically and gratefully accepted her offer while recognizing potential advantages and disadvantages for the research and the emerging personal relationship. During phases two and three I did "homestays" with Seiji's family, interspersed with short trips and stays at a business hotel. Thus, in Japan I participated in Seiji's home environment, whereas in the United States I merely visited. Knowledge of Seiji's home life informed the study in important ways, but for ethical reasons I chose not to put this world under the research microscope.

Settings Given the study's ecological framework, Seiji was both the focus of the research and a guide to the settings of his life in both countries. In both Michigan and Japan, Seiji's family lived in middle-class neighborhoods with good schools. Observations included four full days at Lakeview Elementary School, a public school in Michigan; four full days at the Japanese School of Michigan, a Japanese supplementary school in Michigan; and seven mostly full days at Kaichi Shougakkou, a public elementary school in Japan. My goals during observations were to understand classroom settings and schools as socio-cultural spaces with particular norms and values and to document how Seiji acted and interacted in each setting. Shadowing Seiji through entire days also meant that I was present during transitions, lunch, recess/breaks, and periods before and after school. These times allowed me to interact with Seiji and his friends/classmates. Interviews with Seiji and his family were at his home. During my homestay with Seiji's family, I observed Seiji in a wider range of settings at home and in the neighborhood.

Interviews In the list that follows, the number of interviews with each person is in parentheses: Seiji (7), Aya (5), Shinichi, Seiji's father (1), Mrs. Matthews, Seiji's homeroom teacher at Lakeview (1), Mrs. Jackson, Seiji's language arts teacher at Lakeview (1), Tanaka Sensei, Seiji's homeroom teacher at the Japanese School of Michigan (1), Alexander Sensei, a team teacher at the Japanese School of Michigan (1), Matsumoto Sensei, Seiji's homeroom teacher at Kaichi (2), and Ueda Sensei, Seiji's math teacher at Kaichi (1). I used a form of sociometric questioning in my interviews with Seiji throughout the study because I wanted to learn who he would select to join him in certain situations or for certain activities. I asked Seiji to draw pictures of his neighborhood and create eco-maps that reflected where and with whom he spent time. Almost all of my interactions with Seiji were in English although we occasionally discussed Japanese words and concepts. My interviews with Aya were primarily in English although she occasionally expressed her views in Japanese. I interviewed Seiji's teachers in the

ISSN 2325-6389 
United States in English, and at Kaichi I conducted the interviews in Japanese. All interviews were audio recorded; I transcribed all English language interviews; native Japanese speakers transcribed and translated Japanese language interviews.

Documents I examined various school-related documents including school handbooks, newsletters, and websites. In addition, Aya gave me access to Seiji's kindergarten through fifth grade report cards from Michigan, Michigan Education Assessment Program (MEAP) scores, school essays and drawings, his sixth-grade report card and his yearbook from Kaichi.

\section{Data Analysis}

I privileged Seiji's perspectives and sought to understand them on his terms from the "inside-out" (Corbin \& Strauss, 2008; James, 2013; Sommer, Samuelsson, \& Hundeide, 2010). Analysis was iterative and ongoing. I was aware of the complicated issues related to language, culture, power, and positionality. I took on such tensions through writing memos and reading through my data record (transcripts, field notes, and documents) to test emerging themes. For example, I sought to comparatively analyze the use of particular words-students, peers, children, friends, and classmates - in various settings. My positionality and differences in how I was able to collect data in Japan and the United States - the homestay in Japan and language spoken in the classrooms - mean that my insights on friendship are not completely comparable. The depth and breadth of perspectives I gained from speaking with a wide range of individuals and observing in various settings in the United States and Japan enabled me to understand Seiji more thoroughly. Multiple data sources and multiple methods afforded triangulation both to gain confidence in my interpretation and to see how phenomenon changed or remained the same in various settings (Denzin, 1989; Stake, 1995).

\section{Findings}

I organize findings around these themes: (a) views and experiences of a particular boy, (b) social relationships at Lakeview, and (c) social relationships at Kaichi. Then I share adult priorities in each setting and consider Seiji's analysis. Throughout, I highlight Seiji's friendship formation and adjustment to institutional expectations.

\section{Experiences of a Particular Boy}

Seiji entered Lakeview Elementary School as a non-English speaking kindergartener among mostly American peers. Seiji's parents chose to live in a community without "too much Japanese" in part so that their children would be compelled to speak English at school. Aya reported that although Seiji was a newcomer, everyone immediately made him feel welcome. She also noted that he received targeted English instruction at school upon arrival which allowed him to build both social and cognitive skills. She greatly appreciated these kindnesses and stated that newcomers were likely to be pushed away in Japanese schools.

As is common for most sojourning Japanese children in Michigan, on Saturdays he also attended hoshuuko, a full-day Japanese supplementary school, with nearly 1000 other children. This allowed him to keep up with the Japanese national curriculum in mathematics and Japanese language and participate weekly in Japanese school culture. In addition, Aya noted that Saturdays provided an important opportunity for Seiji to learn "the special language and culture of young people"- something he couldn't learn at home from his parents. 
Attending preschool and the first few months of kindergarten in Japan seemed to shape Seiji's general approach to social interactions. His kindergarten report cards in the United States showed that he was able to establish good social relations with peers as a newcomer. His American teacher wrote, "Seiji is developing nicely in all academic areas. His reading skills are progressing - and he's very excited about it. His English is also developing - and he's becoming more confident as he speaks.... Seiji is a very friendly young man and is kind and liked by all. He's a delight to have in class!" He also seemed to enjoy kindergarten on Saturdays at the Japanese School of Michigan. In an end-of-year letter his Japanese teacher wrote: "You were bright, loved to talk, and liked to take good care of your friends (tomodachi) [translated from the Japanese]." In interviews and in report card comments, Seiji's teachers generally described him as a clever and talkative student with an outgoing, sociable personality and slightly mischievous tendencies. Notably, American teachers addressed their reports to parents and primarily focused on Seiji as an individual. In contrast, Japanese teachers addressed Seiji directly and also referred to him in relationship to the collective.

During the first interview in each phase, I guided Seiji in completing an eco-map depicting the people and places in his daily life in order to learn about his social relationships and daily activities. However, when I analyzed the interview and eco-map together, there was dissonance. Seiji's implicit definition of friends seemed too inclusive. He reported that he had "a lot of friends" and that "playing with friends" was the best part of school, but during our initial 90-minute interview, he did not mention any child by name and only wrote one boy's name on his eco-map. In our second interview, when I asked Seiji to identify three best friends, he listed one American boy from Mrs. Matthew's class and two Japanese boys who had been in his fourth-grade class at the Japanese School of Michigan. After a short discussion with his mother, he added a ChineseAmerican boy he had met at Lakeview and who now attended a magnet school for high performing children. This initial query illuminated the complexity of Seiji's social network, since the boys emerged from three distinct settings. The Japanese boys Seiji listed were primarily Saturday friends. The three buddies attended three different elementary schools, lived in three different cities, and were even in different fifth-grade classes at Saturday school. The Chinese-American boy did not attend any school with Seiji.

His multiple school lives influenced the logistics of his friendships; however, divergent schedules and physical distances were not obstacles to friendship. He looked forward to attending the Japanese School of Michigan even though he had additional homework and tests. Saturdays offered a new network of friends in a new space while enabling him to keep his knowledge of young people's language and culture current. For five and a half years, Sunday was the only day he did not attend school. This schedule lessened his opportunity to interact with friends outside of school while increasing his overall number of classmates and friends. Observations at Lakeview and the Japanese Saturday school also provided limited insights about close friends. He was like a dragonfly-zipping around and among what was interesting, pausing briefly to interact and socialize.

Although Seiji's social networks were more complicated than I had anticipated, he did not view them this way. He cheerfully interacted with other children in whatever context he found them and brokered relationships to have fun and to share mutually enjoyable activities. The sociometric questioning also confirmed this. Seiji valued many characteristics in his classmates, and he therefore selected particular children for particular activities based on particular traits of individual children. For example, when I asked him to name three people with whom he would want to go to 
the library, one of the boys was a quiet boy named Christopher who was a "good reader." At the Japanese School of Michigan, Seiji selected one boy to spend break with, but he later commented, "I wouldn't want him sitting next to me [in class] because he always gets in trouble." The sociometric questioning highlighted Seiji's inclusive and analytic decision making. Inclusive views of friendship were reinforced at home.

In phase one, Aya described a series of incidents that occurred involving "very cute" Japanese pencils, Seiji, and a Lakeview "friend." Aya hypothesized that what transpired was a misunderstanding due to differing cultural views about school supplies. "Japanese students think very important his school supplies," she explained. The tragicomedy commenced when Seiji loaned a Pokémon pencil to a classmate, and it was not returned. Five missing pencils later, there were written exchanges between Aya and the teacher. Aya encouraged Seiji to use a normal yellow pencil, but, she reported, 'He doesn't say 'yes.' He likes Japanese pencil [because American pencils are too hard]." She continued, "So next time he wrote his name on the pencil. So, the friend has his pencil. [Seiji asked] 'Could you return the pencil?' But his friend said, 'It's mine.' [Seiji's] name was erased!" Seiji carved his name into the next pencil, but the "friend" simply carved it out. Classmates were friends regardless of their non-friend-like behavior. I suspected that Seiji (and his mother) had simply translated the Japanese word tomodachi into the English word "friend," while maintaining the Japanese cultural logic. However, in Japan this logic is deeply embedded in the schooling process and is not simply achieved by using a rhetoric of friendship. Next, I focus on Seiji's school contexts as sites of social, emotional, and cognitive learning.

\section{Social Relationships at Lakeview}

During my observations at Lakeview, I did not observe Seiji, or any other students, working in collaborative small groups. The most common arrangements were whole class teaching, pair work, and individual seatwork. That is not to say that small collaborative group work was not used at Lakeview, but unlike at Kaichi, it was not part of the daily routine. Seiji's homeroom teacher Mrs. Matthews explained, "We don't do a lot of group work like we used to. It just doesn't work. You know, we used to do, and we have in the Fall, with the centers. And when you're doing centers you're doing a group." Children were kind to one another in Mrs. Matthews' fifth grade class. I did not observe any incidents of teasing or even mild "rejection" during my days at Lakeview. In fact, exchanging Valentines with classmates, celebrating the birthdays of individual students with festive sugary treats, and the creation of a farewell book for Seiji were strategies that built a classroom community. However, at Lakeview a social curriculum seemed to exist more or less separately from an academic curriculum. Kindness among children was achieved, but it was not explicitly used to promote deep learning. Furthermore, according to Mrs. Matthews, Seiji did struggle when it came to collaborating with peers on school projects: "Whenever he does group work his challenge is to be able to listen to others. He tends to want to do things his way. And he doesn't always want to listen to what someone else wants to suggest, because he thinks he knows the best way and the right way." Although I did not ask, I wondered if Mrs. Matthews implemented specific strategies to help Seiji and other students address this challenge and work together effectively.

"Choice" and "choosing" subtly emerged in the content of lessons and in connection to rules and expectations. In fact, in the lower elementary grades, "makes good choices" is the first item teachers mark in the life skills section of report cards. The Discipline Plan in the school 
handbook warned students: "If you choose to fight, you choose to go home." "Choosing" was also a theme in social relationships. The language arts teacher, Mrs. Jackson, read the class a selection from Chicken Soup for the Kids' Soul in which Kathy Ireland tells the story of her friendless fourth grade year. Her teacher had pulled her aside and explained that she had an obligation to be friendly and improve her friendships.

Mrs. Matthews expressed concern that Seiji seemed to "lack close friendships with students of different backgrounds. He was well liked and friendly, but did not get together - to my knowledge - with school friends of a different background outside of school." She seemed to place a high value on children developing close friendships with other Lakeview students after school hours. Less than two weeks before returning to Japan Seiji commented: 'I don't want to go back to Japan right now because I don't know anyone; I won't know anyone in my school. I have to, like, start from one." However, Aya had been intentional about maintaining relationships with Seiji's preschool friends and their mothers and had arranged play dates during two summers when the family visited Japan. Therefore, Seiji had friends on his first day at Kaichi and in Japan he would also build a broad social network. In Michigan, Aya's chauffeur services were essential for meeting up with friends; at Kaichi everyone was connected to one school, and all friends were geographically accessible by bike or on foot.

\section{Social Relationships at Kaichi}

At the beginning of the school year, Matsumoto Sensei had worried if Seiji, a new student returning to Japan after living abroad for more than five years, would be able to get along with others. However, she quickly realized that it was not a problem. "His personality makes it easier for him to befriend other children," she commented. In addition, Seiji had a "strong command" of both Japanese and English. Support and encouragement from his parents and his own efforts had allowed him to build his Japanese literacy skills. He could respond quickly in the classroom and even "raise the level" of the academic discourse. Seiji's pattern of interacting with many children, including those not mentioned during our conversations and interviews, also continued. Japanese elementary school life is structured to create opportunities for all children to interact academically and socially with a wide range of peers. Students sit in columns of desks facing the front. However, in a matter of seconds they could turn their desks to form their han for small group work or for kyuushoku (Japanese school lunch). Matsumoto Sensei and other Japanese teachers facilitated positive interactions both through han and through interactive class discussions where children actively exchanged ideas with one another and responded to each other's ideas. I observed children giving oral feedback on speeches, evaluating their peers' calligraphy as the teacher held up a child's work, and responding to classmates' answers to math and science problems. Seiji actively participated in these exchanges. He seemed to relish them.

When I asked Matsumoto Sensei about the most difficult challenges newly returning students were likely to face, she said, "The hardest challenge is whether they can break into established friendships." Matsumoto Sensei may have fostered feelings of friendship in the classroom, but established friendships developed over time, through shared experiences, and in the process of experimentation. After returning to Japan, Seiji's cheerful, unabashed exuberance provided him access to numerous groups, but his primary goal was having fun and enjoying new experiences rather than gaining entrée into a particular group. Seiji's classmates were intrigued and enticed by his energy and enthusiasm, and they respected his academic prowess in English and math. However, he did struggle to recognize social and cultural subtleties. For example, in 
regard to omoiyari, or awareness and sensitivity to other people's needs and feelings and response to fulfill those needs or accommodate those feelings, he was still a novice. This is important because in all Japanese social relationships, learning to intuit and modify selfexpression and behavior according to context is a critical skill.

Seiji may have been frustrated when other children or adults did not respond to his ideas in ways that he wanted or hoped, but during our interviews he always seemed to be seekingand finding - the good in people. The following exchange occurred during phase two after Seiji had been attending school in Japan for four months:

Amy: Is there anybody in your class who's difficult to get along with?

Seiji: Um, not really, but sometimes there's like things that don't go together.

Amy: You mean, people's ideas don't go together?

Seiji: Yeah, or

Amy: Personalities?

Seiji: It's not that I'm not good friends with everybody.

A hint of disharmony perhaps, but overall, Seiji maintained his inclusive view of friendship.

Matsumoto Sensei's top priority in the classroom was human relations because feelings of friendship in the classroom facilitated both academic and social learning. Overnight school trips $^{2}$, human pyramids on sports day, and seemingly never-ending graduation rehearsals were all exercises in building nakama. Seiji was part of these activities in sixth grade, but he had missed five years of nakama-building activities with his Kaichi age-mates. During my final interview with Matsumoto Sensei, after the school year was over, she commented: "Speaking about friendship (tomodachi kankei), his way of thinking is still immature, so he did not need someone (nakama) to trust and support him, or he did not become such a friend to anyone. He was not in a situation where he supported someone. He had many friends (tomodachi) with whom he could have fun every day." Matsumoto Sensei seemed to suggest that although Seiji had not yet encountered situations that had provided him opportunities to develop and desire reciprocal personal friendship, someday he would.

\section{Classroom Priorities: Human Relations and Independent Learning}

The Japanese language has many words for friend, although the nuance differs. My interviews and conversations with Seiji were primarily in English and when Seiji referred to his peers he always referred to them as "friends." In other words, he did not talk about "classmates," "peers," "other kids," "best friends," "close friends" or "other students." In phase three, we explicitly discussed Japanese words related to friends and social relationships:

Amy: What are the different words in Japanese for friend?

Seiji: Tomodachi.

Amy: Hai. [Yes.] And I think like yujin.

Seiji: Ohh! Yujin. Shinyuu is like best friend.

Amy: And nakama wa? [What about nakama?] 
Seiji: Tomodachi and nakama are not really the same. Tomodachi is friend. Nakama is like in your team.

Amy: So, who would be in your team? Is that your class?

Seiji: Yeah.

Amy: Is your whole class-

Seiji: Nakama.

Amy: Nakama.

Seiji: Yeah. They're all friends. Maybe you have to be friends to be nakama. I don't know.

Amy: Then everybody in the class is your friend?

Seiji: Not actually that, but yeah, kind of.

Amy: So is that maybe a difference between nakama and tomodachi...

Seiji: Nakama is a little lower level, maybe, than tomodachi.

Seiji grappled with his own thinking about these concepts in translation as we spoke. His view that nakama is "a little lower level" than tomodachi may reflect a lesser commitment to the un-chosen group. Teachers in Japan seemed to blur their use of the word tomodachi in order to create interdependence and feelings of friendship among children in the same class because they were groups of people that did not choose to be together but nevertheless belonged together. Perhaps children learned how to interact, share, communicate, and endure joys and hardships together initially because of obligation. Over time and with a consistent message, some degree of affection emerged.

Matsumoto Sensei reflected, "I want them to learn consideration for others (omoiyari) and kindness (yasashisa). I think kindness is strength." She insisted that ningen kankei (human relations) was the most important thing that children learned in her classroom: "They come all the way to school, so learning means learning with their friends (tomodachi). Experiencing the joy of learning collaboratively with friends (tomodachi) is important for school." Mrs. Matthews also wanted her students to learn from each other, but providing opportunities for them to "be independent learners, to think on their own" was a higher priority. She implemented policies such as "if you raise your hand, you have the floor to speak." She noted that Seiji's class was social and very verbal: "If they think they're right, they're persistent to the point that sometimes you might have to say 'Okay, stop!' and kind of redirect." In Mrs. Matthew's class, students were social, but generally not around learning. My observations in both settings and my conversations with Seiji corroborated these priorities.

\section{Discussion}

For children around the world both in and out of school, friends are important: "For them, friends mean fun" (Cambridge Primary Review and Alexander, 2010, p. 65). Seiji was academically successful in both the United States and Japan, but what he liked most about school was the opportunity to interact with other children: "My friends are funny and fun to be with." As Seiji journeyed from Japan to the United States and back to Japan, he identified friends 
wherever he went. This approach served him well. He gained language skills and cultural knowledge from his peer groups. Seiji's social experiences in the United States, and in Japan prior to that, were part of the social knowledge he possessed (Corsaro \& Eder, 1990). In a Japanese preschool, he learned that everyone was a friend, and at Lakeview he learned to interact with friends who had different cultural backgrounds and different skin colors. He also experienced and then adopted the idea of being kind to and helping newcomers.

There is a risk that social emotional learning in the United States becomes another program to implement or another way to measure and address individual competency or deficit (Hoffman, 2009). Seiji's experiences guide us to focus on classrooms and schools as relational contexts where friendship is built. In Japanese, there is a distinction between tomodachi (friends) and kojinteki na tomodachi (personal friendship). In this paper, I argue that working toward school friendships, broadly conceived, can work toward building classroom community and a positive school environment where "everyone can play" and learn. Japanese preschool and elementary school, teachers place a high priority on developing feelings of friendship at the classroom level because it is pedagogically useful and culturally important (Cave, 2007; Lewis, 1995; Sato, 2004; Tobin, Hsueh, \& Karasawa, 2009). Although friends can be beneficial or detrimental (Hartup, 1996), school friends, as conceptualized in this paper, are beneficial in part because, under the guidance of an expert teacher, they can foster cognitive skills at the whole class level:

The uniquely motivating quality of 'friendly competition' during collaboration, as well as the greater motivation to persist in the face of difficulty in the context of an emotionally supportive relationship; the mutual commitment and loyalty between friends which motivates children's concerted attempts to comprehend one another's ideas and perspectives, which may in turn stretch both the listener's understanding and the speaker's communication skills; the safety and security of airing one's untested ideas in a climate of acceptance, shared positive affect and good humor, and the corresponding lack of defensiveness that may promote thoughtful justifications, revisions, and elaborations of one's ideas. (Gifford-Smith \& Brownell, 2003, p. 259)

In the United States, elementary school teachers generally encourage amiable relationships among students, although perhaps too often they "become so centered on interacting with the children themselves that they fail to recognize opportunities to help children increase their friendship skills with peers" (Kostelnik et al, 1998, p. 221). Some warn that obvious tampering with students' peer relations can have negative outcomes for children (Audley-Piotrowski, Singer, \& Patterson, 2015). This may be the case if teachers try to engineer personal friendships. In the United States, friendship is widely perceived as a matter of personal choice, and many will argue that it lies outside of teachers' professional responsibilities. However, the invisible hand of teachers can intentionally create institutional expectations and promote collegiality so that children can build supportive peer ecologies (Farmer, Lines, \& Hamm, 2011; Gest \& Rodkin, 2011). Attending to children's desires for friendship and membership in a classroom community is a practical strategy for facilitating learning in and among all children and improving the overall school environment. When elementary school children experience feelings of friendship in the classroom, it enhances their social and academic skills, their confidence, and their sense of belonging. 
There are important differences between public education in Japan and the United States. High-stakes testing, commitment to the individual, and the comparative heterogeneity of classrooms are important contextual factors when considering what goes on in elementary schools in the United States. In addition, I recognize that classrooms and schools in each country vary. Nevertheless, an interest in the procedures and potential promise of Japanese classrooms has emerged at various times since the 1980s (see, Green, 2014; Hiebert \& Stigler, 2017; Leestma \& Dorfman, 1987; Stigler \& Hiebert, 1999). I suspect that when rich conversations around academic content occur in Japanese classrooms it is because students have been explicitly taught civility in exchanges with classmates. They have been taught to think about their peers as friends who are on their team.

In the United States, when teachers encounter children with poor or undeveloped social skills and few friends, individual intervention, medication, consultation with parents and professionals are common responses. These may be reasonable, if reactive, strategies for individual teachers. Nevertheless, to what extent might American elementary school teachers consciously and collectively lead children to behave in ways that optimize everyone's sense of belonging and ability to achieve and contribute to the learning endeavor? Classmates are not simply playmates. They are also partners in learning and companions in the activities that compose school life. Teachers can set up systems where children help newcomers learn cultural knowledge, language, skills and content so that they can more quickly become part of the learning community. Books such as Carrie Goldman's (2012) Bullied: What Every Parent, Teacher, and Kid Needs to Understand about Ending the Cycle of Fear are written at least in part to give parents and kids tools to address bullying when administrators and teachers have failed to create a safe learning environment for all.

\section{Conclusion}

As an "ethnography of the particular" (Abu-Lughod, 1991) the broader study from which this paper draws seeks to understand one boy's experiences transitioning between going to school and living in the United States and going to school and living in Japan. His particular experiences are (and must be) unique. The limitations of case study research also constitute its strength. Although Seiji's "case" may be atypical, his experiences and ideas about friendship invite readers to reconsider and possibly modify their previous generalizations and assumptions (Stake, 1995) about friendship in classrooms. This paper focuses on school friends, although the focus of the broader study was not solely on this topic. Thus, Seiji was the only non-adult I interviewed. I observed Seiji in interaction with his classmates both in and out of school, one-onone and in small and large groups, but I didn't talk to other children about their relationships or interactions with Seiji or about their views on friendship. Finally, although I was able to observe Seiji's interactions with peers in many contexts over a 15-month period, all settings were not open to me and my time in particular settings was limited. Thus, this account of one boy's ideas and experiences is partial.

Seiji's ideas and experiences in both systems suggest how educators in the United States might adopt and then intentionally teach students the necessary skills and dispositions to create "safe, caring, and participatory schools" (Cohen, 2014). Building broad feelings of friendship in classrooms and schools is good for children's learning and overall development. Economic 
constraints and increasing student diversity call for approaches to schooling that maximize children's abilities to assist and learn from one another. The teacher need not be the sole source of comfort, support, guidance, and feedback for each child. Moving away from a paradigm of "learning to live in a crowd" (Jackson 1968/1990, p. 10) and toward education that meets “children's needs-for friendship, for belonging, for opportunities to shape school life" (Lewis, 1995, p. 1) can improve school climate and student learning. This, in turn, can help to lay the foundation for an engaged citizenry where individuals have the skills and inclination to communicate, collaborate, and compromise with diverse individuals. 
Journal of Family Diversity in Education

Volume 2 Number 42017

http://familydiversityeducation.org/index.php/fdec

\section{References}

Abu-Lughod, L. (1991). Writing against culture. In R. G. Fox (Ed.), Recapturing anthropology: Working in the present (pp. 137-162). Santa Fe, NM: School of American Research Press.

Alderson, P. (1995). Listening to children: Children, ethics and social research. London: Barnardos.

Alexander, R. (2000). Culture and pedagogy: International comparisons in primary education. Malden, MA: Blackwell Publishing.

Audley-Piotrowski, S., Singer, A., \& Patterson, M. (2015). The role of the teacher in children's peer relations: Making the invisible hand intentional. Translational Issues in Psychological Science, 1(2), 192-200. https://doi.org/10.1037/tps0000038

Bagwell, C. L., \& Schmidt, M. E. (2013). Friendships in childhood and adolescence. Guilford Press.

Bell, S., \& Coleman, S. (Eds.). (1999). The anthropology of friendship. Oxford: Berg.

Bierman, K. L., \& Powers, C. J. (2009). Social skills training to improve peer relations. In K. H. Rubin, W. M. Bukowski, \& B. Laursen (Eds.). Handbook of peer interactions, relationships, and groups (603-621). New York, The Guilford Press.

Blatchford, P., Pellegrini, A. D., \& Baines, E. (2015). The child at school: Interactions with peers and teachers. New York: Routledge.

Blatchford, P., Bassett, P., \& Brown, P. (2005). Teachers' and pupils' behavior in large and small classes: A systematic observation study of pupils aged 10 and 11 years. Journal of Educational Psychology, 97(3), 454-467. https://doi.org/10.1037/0022-0663.97.3.454

Bronfenbrenner, U. (1972). Two worlds of childhood: U.S. and U.S.S.R. New York: Simon and Schuster.

Bronfenbrenner, U. (1979). The ecology of human development: Experiments by nature and design. Cambridge, MA: Harvard University Press.

Brown, P. M., Corrigan, M. W., \& Higgins-D’Alessandro, A. (2012). Handbook of prosocial education. Blue Ridge Summit, PA: Rowman and Littlefield Publishing Group.

Cambridge Primary Review (Organization), \& Alexander, R. J. (2010). Children, their world, their education: The final report and recommendations of the Cambridge Primary Review. New York: Routledge.

Cave, P. (2007). Primary school in Japan: Self, individuality and learning in elementary education. New York: Routledge.

Centers for Disease Control and Prevention. (2009). School connectedness: Strategies for increasing protective factors among youth. Retrieved from http://www.cdc.gov/HealthyYouth/AdolescentHealth/pdf/connectedness.pdf

Cohen, J. (2014). The foundation for democracy: School climate reform and prosocial education. Journal of Character Education, 10(1), 43-52. 
Collaborative for Academic, Social, and Emotional Learning. What is SEL? http://www.casel.org/what-is-sel/ (accessed 6/4/17).

Corbin, J., \& Strauss, A. (2008). Basics of qualitative research: Techniques and procedures for developing grounded theory. Thousand Oaks, Calif: Sage.

Corsaro, W. A., \& Eder, D. (1990). Children's peer cultures. Annual Review of Sociology, 16(1), 197-220.

Damrow, A. L. (2014). Navigating the structures of elementary school in the United States and Japan: An ethnography of the particular. Anthropology \& Education Quarterly, 45(1), 87104.

Denzin, N. K. (1989). The research act: A theoretical introduction to sociological methods. Englewood Cliffs, N.J: Prentice Hall.

Emond, R. (2005). Ethnographic research methods. In S. Greene \& D. Hogan (Eds.), Researching children's experiences: Approaches and methods. London: Sage.

Erickson, F. \& Shultz, J. (1991). Students of the curriculum. In P. W. Jackson (Ed.), Handbook of research on curriculum: A project of the American Educational Research Association (465-485). New York: Macmillan.

Farmer, T. W., Lines, M. M., \& Hamm, J. V. (2011). Revealing the invisible hand: The role of teachers in children's peer experiences. Journal of Applied Developmental Psychology, 32(5), 247-256. https://doi.org/10.1016/j.appdev.2011.04.006

Furrer, C., Skinner, E. A., \& Pitzer, J. R. (2014). The influence of teacher and peer relationships on students' classroom engagement and everyday motivational resilience. National Society for the Study of Education, 113(1), 101-123.

Gest, S., \& Rodkin, P. (2011). Teaching practices and elementary classroom peer ecologies. Journal of Applied Developmental Psychology, 32(5), 288-296. https://doi.org/10.1016/j.appdev.2011.02.004

Gifford-Smith, M. E. \& Brownell, C. A. (2003). Childhood peer relationships: Social acceptance, friendships, and peer networks. Journal of School Psychology, 41, 235-284. https://doi.org/10.1016/S0022-4405(03)00048-7

Goldman, C. (2012). Bullied: What every parent, teacher, and kid needs to know about ending the cycle offear. New York: HarperOne.

Graue, M. E., \& Walsh, D. J. (1998). Children in context: Theories, methods, and ethics. Thousand Oaks, CA: Sage.

Green, E. (2014). Building a better teacher: How teaching works (and how to teach it to everyone). New York: W.W. Norton \& Company.

Grusec, J. E. \& Hastings, P. D. (2007). Handbook of socialization: Theory and research. New York: The Guilford Press.

Harding, S. (1987). Feminism and methodology: Social science issues. Bloomington: Indiana University Press. 
Hartup, W. W. (1996). The company they keep: Friendships and their developmental significance. Child development, 67(1), 1-13.

Hedegaard, M. (2009). Children's development from a cultural-historical approach: Children's activity in everyday local settings as foundation for their development. Mind, Culture, and Activity, 16(1), 64-82. https://doi.org/10.1080/10749030802477374

Hedegaard, M., Aronsson, K., Højholt, C., \& Ulvik, O. S. (Eds.). (2012). Children, childhood and everyday life: Children's perspectives. IAP.

Hedegaard, M., \& Fleer, M. (2008). Studying children: A cultural-historical approach. Maidenhead, Berkshire: McGraw Hill/Open University Press.

Hendry, J. (1986). Becoming Japanese. Honolulu: University of Hawaii Press.

Hiebert, J., \& Stigler, J. W. (2017). Teaching versus teachers as a lever for change: Comparing a Japanese and a US perspective on improving instruction. Educational Researcher, 46(4), 169-176.

Hoffman, D. M. (2009). Reflecting on social emotional learning: A critical perspective on trends in the United States. Review of Educational Research, 79(2), 533-556. https://doi.org/10.3102/0034654308325184

Jackson, P. W. (1968/1990). Life in classrooms (Reprint ed.). New York: Teachers College Press.

James, A. (2013). Socialising children. London: Palgrave MacMillan.

Kanno, Y. (2003). Negotiating bilingual and bicultural identities: Japanese returnees betwixt two worlds. Mahwah, NJ: Lawrence Erlbaum Associates.

Kirova, A. (2007). Moving childhoods: Young children's lived experiences of being between languages and cultures. In L. D. Adams \& A. Kirova (Eds.), Global migration and education: Schools, children, and families (pp. 185-202). Mahwah, NJ: Lawrence Erlbaum Associates.

Kirsch, G. (1999). Ethical dilemmas in feminist research: The politics of location, interpretation and publication. Albany: State University of New York.

Kondo, D. K. (1990). Crafting selves: Power, gender, and discourses of identity in a Japanese workplace. Chicago: University of Chicago Press.

Kostelnik, M. J., Stein, L. C., Whiren, A. P., Soderman, A. (1998). Guiding children's social development. New York: Delmar Publishers.

Leestma, R., \& Dorfman, C. H. (1987). Japanese education today. US Department of Education.

Lewis, C. C. (1995). Educating hearts and minds: Reflections on Japanese preschool and elementary education. Cambridge: Cambridge University Press.

Ma, W. (2010). Bumpy journeys: A young Chinese adolescent's transitional schooling across two sociocultural contexts. Journal of Language, Identity, and Education, 9(2), 107-123. https://doi.org/10.1080/15348451003704792 
Narratives of Migrant Women

Melnick, H., Cook-Harvey, C. M., \& Darling-Hammond, L. (2017). Encouraging social and emotional learning in the context of new accountability. Palo Alto, CA: Learning Policy Institute.

Morita, Y., Soeda, H., Soeda, K. \& Taki, M. (1999). Japan. In P.K. Smith, Y. Morita, J. JungerTas, D. Olweus, R. Catalano, \& P. Slee (Eds.), The nature of school bullying (pp. 309-323). London and New York: Routledge.

National School Climate Center (n.d.). Interpersonal relationships. Retrieved from: http://www.schoolclimate.org/guidelines/interpersonal_relationships.php

Noddings, N. (1992). The challenge to care in schools. New York: Teachers College Press.

Paley, V. G. (1993). You can't say you can't play. Cambridge, Mass: Harvard University Press.

Peak, L. (1991). Learning to go to school in Japan: The transition from home to preschool life. Berkeley: University of California Press.

Rubin, K. H., Bukowski, W. M., \& Laursen, B. (Eds.) (2009). Handbook of peer interactions, relationships, and groups. New York, The Guilford Press.

Sato, N. E. (2004). Inside Japanese classrooms: The heart of education. New York: Routledge/Falmer.

Schneider, B. (2016). Childhood friendships and peer relations: Friends and enemies. New York: Routledge.

Slavin, R. E. (1995). Cooperative learning: Theory, research, and practice. Boston: Allyn and Bacon.

Smith, B. H., \& Low, S. (2013). The role of social-emotional learning in bullying prevention efforts. Theory Into Practice, 52(4), 280-287. https://doi.org/10.1080/00405841.2013.829731

Sommer, D., Samuelsson, I. P., \& Hundeide, K. (2010). Child perspectives and children's perspectives in theory and practice. Dordrecht: Springer.

Stake, R. E. (1995). The art of case study research. Thousand Oaks, CA: Sage Publications.

Stigler, J. W., \& Hiebert, J. (1999). The teaching gap: Best ideas from the world's teachers for improving education in the classroom. New York: Free Press.

Thapa, A., Cohen, J., Guffey, S., \& Higgins-D’Alessandro, A. (2013). A review of school climate research. Review of Educational Research, 83(3), 357-385. https://doi.org/10.3102/0034654313483907

Tobin, J., Hsueh, Y. \& Karasawa, M. (2009). Preschool in three cultures revisited: China, Japan, and the United States. Chicago: University of Chicago Press.

Tobin, J. J., Wu, D. Y. H., \& Davidson, D. H. (1989). Preschool in three cultures: Japan, China, and the United States. New Haven, CT: Yale University Press.

Tsuneyoshi, R. (2001). The Japanese model of schooling: Comparisons with the United States. New York: Routledge.

Usher, R. (2000). Feminist approaches to a situated ethics. In H. Simons \& R. Usher (Eds.), Situated ethics in educational research (22-38). London: Routledge. 
Wolf, M. (1992). A thrice-told tale: Feminism, postmodernism, and ethnographic responsibility. Stanford, Calif: Stanford University Press.

Yoneyama, S. \& Naito, A. (2003). Problems with the paradigm: The school as a factor in understanding bullying (with special reference to Japan). British Journal of Sociology of Education, 24(3), 315-330. https://doi.org/10.1080/01425690301894

Zins, J. E., Bloodworth, M. R., Weissberg, R. P., \& Walberg, H. J. (2007). The scientific base linking social and emotional learning to school success. Journal of Educational and

Psychological Consultation, 17(2-3), 191-210. https://doi.org/10.1080/10474410701413145

\section{Notes:}

${ }^{1}$ All names in this description are pseudonyms. Seiji was ten years old at the start of the research and twelve years old when I concluded my fieldwork.

${ }^{2}$ While at Lakeview the school trip was an end-of-the-year "reward," at Kaichi it was a middleof-the-year class-building exercise. 